\title{
Efficacy of Pulsed Dye Laser Plus Topical Calcipotriol and Corticosteroid \\ Combination versus Topical Calcipotriol and Corticosteroid Combination Alone in Treatment of Nail Psoriasis \\ Azmy Ahmed Abdel-latif, Ibrahim Mearaj Ibrahim, Shady Mahmoud, \\ Walaa Abdel-hady Awwad Mahgoub* \\ Department of Dermatology and Venereology, Faculty of Medicine, Al-Azhar University \\ *Corresponding author: Walaa Abdel-hady Awwad Mahgoub, Email: W_prp@yahoo.com,
}

Mobile: (+20) 01065468814

\begin{abstract}
Background: psoriasis is a chronic, inflammatory skin disease that causes significant distress and morbidity.

Objective: the aim of this study was to compare the efficacy of PDL plus topical calcipotriol and corticosteroid combination versus topical calcipotriol and corticosteroid combination in the treatment of nail psoriasis.

Patients and methods: thirty patients with bilateral fingernail psoriasis were recruited from the Dermatology Outpatient Clinic at Al Hussein Hospital, Al Azhar University and Al-Haud Al-Marsoud Hospital between September 2014 and February 2017.

Results: regarding treatment sessions, total treatment sessions, follow up sessions or total follow up sessions, there was no statistically significant difference (p-value $>0.05)$ between right hand and left hand. There was no statistically significant difference ( $\mathrm{p}$-value $>0.05$ ) between the 2 subgroups (<30 years and $>30$ years), (male and female) or (skin type 3 and type 4 ) as regard $1^{\text {st }}, 2^{\text {nd, }}$ and $3^{\text {rd }}$ treatment session. There was highly statistically significant (p-value $<0.001$ ) positive correlation between (1st Rt. Vs 2nd Rt.) and (2nd Rt. Vs 3rd Rt.) treatment sessions. Also, statistically significant (p-value < 0.05 ) positive correlation between (first Rt. Vs 3rd Rt.) treatment sessions.

Conclusion: laser therapy had been shown to be effective and safe for nail psoriasis. It could be used alone or combined with different therapeutic modalities, being especially beneficial with topical treatments.
\end{abstract}

Keywords: Pulsed Dye Laser Plus, Topical calcipotriol, Corticosteroid combination, Psoriasis.

\section{INTRODUCTION}

Psoriasis is an immunologic disease with a genetic predisposing predominantly triggered by abnormal CD4 and CD8 T-cell expansion. This activation eventually leads to the infiltration of inflammatory cells into the epidermis, resulting in the characteristic cutaneous lesions found in psoriasis. The maintenance of these lesions requires an expanded superficial vascular network, which begins prior to the onset of lesion formation (1). Psoriasis varies in presentation and can involve the skin, joints, and nails, either alone or in combination. Nail psoriasis is common in those suffering from psoriasis, with reported incidences varying from $10 \%$ to $78 \%{ }^{(2)}$. Nail involvement is more commonly found in patients with psoriatic arthropathy than in those with uncomplicated psoriasis ${ }^{(3)}$.

The nail lesions were identified as nail matrix disease (pitting, leukonychia, red spots in lunula, nail plate crumbling) and nail bed disease (oil drop discoloration, onycholysis, nail bed hyperkeratosis, splinter hemorrhage). The Nail Psoriasis Severity Index (NAPSI) is an objective numeric grading tool used to evaluate disease severity. To obtain a patient's NAPSI score, the nail is divided into 4 quadrants; each quadrant then is evaluated based on the presence or absence of signs of the nail bed and/or nail matrix disease and is given a score.

The sum of the individual scores for each quadrant is the patient's NAPSI score ${ }^{(4)}$. Nail psoriasis has a significant adverse influence on the quality of life of patients. De Jong and colleagues ${ }^{(5)}$ reported that 93\% of patients with psoriasis with nail disease considered their condition to be a significant cosmetic handicap, 58\% found that it interfered with their job, and $52 \%$ described the pain as a symptom ${ }^{(6)}$.

The treatment of nail psoriasis largely depends on the severity of symptoms. Local or topical therapies along with ultraviolet (UV) therapy should be attempted initially. However, the efficacy of these methods is limited, as penetration through the nail plate and nail matrix is difficult. Systemic therapy may be needed in patients with severe disease or if topical treatment fails. Systemic treatment is not recommended for patients with psoriasis limited to the nails ${ }^{(7)}$.

In 2009, Fernandez-Guarino et al. ${ }^{(8)}$ were the first to study the efficacy of $595 \mathrm{~nm}$ pulsed dye laser (PDL) in nail psoriasis treatment, using a 6-millisecond pulse duration which is longer than the pulse duration used in previous psoriasis vulgaris studies. The study revealed excellent results, with a $33 \%$ improvement after 12 weeks of monthly sessions and 58\% improvement after 24 weeks of treatment from the PDL treatment group.

A more recent study, Oram et al. ${ }^{(9)}$ used a 1.5millisecond pulse duration, which also demonstrated good results of PDL treatment of nail psoriasis ${ }^{(7,9)}$.

\section{AIM OF THE STUDY}

The aim of this study was to compare the efficacy of PDL plus topical calcipotriol and corticosteroid 
combination versus topical calcipotriol and corticosteroid combination in the treatment of nail psoriasis.

\section{PATIENTS AND METHODS \\ Patient Selection}

Thirty patients with bilateral fingernail psoriasis were recruited from the Dermatology Outpatient Clinic at Al Hussein Hospital, Al Azhar University and Al-Haud Al-Marsoud Hospital. The study was conducted between September 2014 and February 2017.

\section{Ethical approval:}

The study was approved by the Ethics Board of Al-Azhar University and an informed written consent was taken from each participant in the study.

The diagnosis was based upon the clinical characteristics of nail psoriasis. Patients with nail psoriasis that was refractory to the treatment they were receiving could be included in our study.

Exclusion criteria: - Pregnancy or lactation and history of photosensitivity.

- Patients who discontinued or just started to receive new systemic therapy or phototherapy during the study period were dropped from the study.

\section{Study Protocol}

The patients' characteristics and medical history were recorded. Each patient received topical calcipotriol and corticosteroid combination daily for six months on both hands. One session of $595 \mathrm{~nm}$ PDL was applied on the right hand every month for six months. Spots were directed to lunula, proximal and lateral nail fold.

Modified NAPSI scores were calculated and digital photographs of the nails were taken at baseline, 3 months and 6 months. Patients who used topical agents to treat plaque psoriasis elsewhere on the body were instructed to avoid transfer to the fingernails ${ }^{(\mathbf{1 0})}$.

\section{Efficacy and Safety Assessment}

Modified NAPSI were assessed at baseline, 3 months and 6 months from digital photographs. Modified NAPSI scores were evaluated for the nail matrix, nail bed, and total nail of each finger. The highest possible score was 8 for the nail matrix, 6 for the nail bed, and 14 for the whole nail (the sum of the nail matrix and nail bed scores) ${ }^{(\mathbf{1 0})}$.

As recommended in the guidelines for clinical trials on psoriasis, another blinded dermatologist evaluated the physician's global assessment scores as an outcome parameter using digital photographs at 3 and 6 months. Improvement of the fingernail was scored on a scale from 0 to 6 (0: total clearance [100\% improvement]; 1: almost total clearance $[90 \%$ improvement]; 2: distinct clearance $[75 \%$ improvement]; 3: moderate clearance [50\% improvement]; 4: mild clearance [25\% improvement], and 5: no change, 6: worse).

\section{Statistical analysis:}

Data were analyzed using Statistical Program for Social Science (SPSS) version 15.0. Quantitative data were expressed as mean \pm standard deviation (SD). Qualitative data were expressed as frequency and percentage.

\section{The following tests were done:}

Independent-samples t-test of significance was used when comparing two means. A one-way analysis of variance (ANOVA) was used when comparing more than two means. Pearson's correlation coefficient (r) was used for correlating data.

Probability (P-value)

- P-value $<0.05$ was considered significant.

- P-value $<0.001$ was considered as highly significant.

- P-value >0.05 was considered insignificant.

\section{RESULTS}

Table (1): Description of demographic data

\begin{tabular}{|c|c|c|}
\hline \multicolumn{2}{|c|}{ Demographic data } & Studied patients $(\mathrm{N}=\mathbf{3 0})$ \\
\hline \multirow{4}{*}{ Age (Years) } & Mean & 24.5 \\
\hline & \pm SD & 14.9 \\
\hline & Min & 6 \\
\hline & Max & 65 \\
\hline \multirow{2}{*}{ Gender } & Male & $7(23 \%)$ \\
\hline & Female & $23(77 \%)$ \\
\hline \multirow{2}{*}{ Skin type } & Type 3 & $9(30 \%)$ \\
\hline & Type 4 & $21(70 \%)$ \\
\hline
\end{tabular}

Table (1) showed that the mean age of studied patients was $24.5 \pm 14.9$ years. $77 \%$ of the studied patients were females and the other $23 \%$ were males. Regarding skin type, $70 \%$ of studied patients were type 3 and the other $30 \%$ were type 4 .

Table (2): Comparison between total mNAPSI score of $\mathrm{Rt}$ and $\mathrm{Lt}$ hand in treatment sessions as regard age

\begin{tabular}{|c|c|c|c|c|}
\hline \multicolumn{2}{|l|}{ Variables } & $\begin{array}{c}<30 \\
\text { Years } \\
(\mathbf{N}=\mathbf{2 0})\end{array}$ & $\begin{array}{c}>30 \\
\text { years } \\
(\mathbf{N}= \\
10)\end{array}$ & $\begin{array}{c}\text { T-test } \\
\text { p- } \\
\text { value }\end{array}$ \\
\hline \multirow{2}{*}{$\begin{array}{l}\text { pretreatment } \\
\text { Total score }\end{array}$} & Mean & 31.8 & 39.7 & \multirow{2}{*}{0.3} \\
\hline & $\pm \mathrm{SD}$ & 10.1 & 22.6 & \\
\hline \multirow{2}{*}{$\begin{array}{c}3^{\text {rd }} \text { session Total } \\
\text { score }\end{array}$} & Mean & 26.2 & 34 & \multirow{2}{*}{0.1} \\
\hline & $\pm \mathrm{SD}$ & 11.1 & 18.2 & \\
\hline \multirow{2}{*}{$\begin{array}{l}6^{\text {th }} \text { session Total } \\
\text { score }\end{array}$} & Mean & 28.7 & 32.6 & \multirow{2}{*}{0.5} \\
\hline & $\pm \mathrm{SD}$ & 18.7 & 11.5 & \\
\hline
\end{tabular}

This table showed no statistical significant difference (p-value $>0.05)$ between the 2 subgroups $(<30$ years 
and $>30$ years) as regard pretreatment, $3^{\text {rd }}$ and $6^{\text {th }}$ treatment session.

Table (3): Comparison between total mNAPSI score of Rt and Lt hand in treatment sessions as regard sex

\begin{tabular}{|c|c|c|c|c|}
\hline Variables & Groups & $\begin{array}{c}\text { Male } \\
(\mathbf{N}= \\
\mathbf{8})\end{array}$ & $\begin{array}{c}\text { Female } \\
(\mathbf{N}= \\
\mathbf{2 2})\end{array}$ & $\begin{array}{c}\text { T-test } \\
\text { p- } \\
\text { value }\end{array}$ \\
\hline \multirow{2}{*}{$\begin{array}{c}\text { pretreatment } \\
\text { Total score }\end{array}$} & Mean & 31.6 & 35.5 & \multirow{2}{*}{0.5} \\
\hline & \pm SD & 16.5 & 15.3 & \\
\hline \multirow{2}{*}{$\begin{array}{c}3^{\text {rd }} \text { session Total } \\
\text { score }\end{array}$} & Mean & 30.2 & 28.3 & \multirow{2}{*}{0.7} \\
\hline & \pm SD & 18.2 & 12.7 & \\
\hline \multirow{2}{*}{$\begin{array}{c}6^{\text {th }} \text { session Total } \\
\text { score }\end{array}$} & Mean & 37.5 & 27.3 & \multirow{2}{*}{0.1} \\
\hline & \pm SD & 24.1 & 12.5 & \\
\hline
\end{tabular}

This table showed no statistical significant difference (p-value > 0.05) between the 2 subgroups (male and female) as regards treatment session.

Table (4): Comparison between total mNAPSI score of Rt and Lt hand in treatment sessions as regard skin type

\begin{tabular}{|c|c|c|c|c|}
\hline \multicolumn{2}{|l|}{ Variables } & $\begin{array}{c}\text { Type } \\
\mathbf{3} \\
(\mathbf{N}= \\
9)\end{array}$ & $\begin{array}{c}\text { Type } 4 \\
(\mathbf{N}= \\
21)\end{array}$ & $\begin{array}{c}\text { T-test } \\
\text { p- } \\
\text { value }\end{array}$ \\
\hline \multirow{2}{*}{$\begin{array}{l}\text { pretreatment Total } \\
\text { score }\end{array}$} & Mean & 29.7 & 36.5 & \multirow{2}{*}{0.3} \\
\hline & $\pm \mathrm{SD}$ & 9.7 & 17.2 & \\
\hline \multirow{2}{*}{$\begin{array}{c}3^{\text {rd }} \text { session Total } \\
\text { score }\end{array}$} & Mean & 23.7 & 31.1 & \multirow{2}{*}{0.2} \\
\hline & $\pm \mathrm{SD}$ & 12.7 & 14.3 & \\
\hline \multirow{2}{*}{$\begin{array}{c}6^{\text {th }} \text { session Total } \\
\text { score }\end{array}$} & Mean & 24.1 & 32.6 & \multirow{2}{*}{0.2} \\
\hline & \pm SD & 15.7 & 16.6 & \\
\hline
\end{tabular}

Table (4) showed no statistical significant difference (p-value >0.05) between the 2 subgroups (skin type 3 and type 4) as regards treatment session.

Table (5): Correlation study between mNAPSI score of treatment sessions as regard Rt. Hand

\begin{tabular}{||c||c|c||}
\hline \multicolumn{1}{|c|}{ Groups } & \multicolumn{2}{c|}{$\begin{array}{c}\text { Pearson } \\
\text { correlation } \\
\text { coefficient }\end{array}$} \\
\cline { 2 - 3 } Parameters & $(\mathbf{r})$ & p-value \\
\hline \hline pretreatment Rt. Vs 3rd Rt. & $\mathbf{0 . 8}$ & $<\mathbf{0 . 0 0 1} * *$ \\
\hline \hline pretreatment ${ }^{\text {t }}$ Rt. Vs 6th Rt. & $\mathbf{0 . 4}$ & $\mathbf{0 . 0 2} *$ \\
\hline \hline 3rd Rt. Vs 6th Rt. & $\mathbf{0 . 6}$ & $<\mathbf{0 . 0 0 1} * *$ \\
\hline
\end{tabular}

(r): Pearson correlation coefficient

$*$ : -value $<0.05$ is considered significant.

$* *$ : $\mathrm{p}$-value $<0.001$ is considered highly significant.

This table showed:

- Highly statistical significant (p-value $<0.001)$ positive correlation between $1^{\text {st }}$ Rt. Vs $2^{\text {nd }}$ Rt. and $2^{\text {nd }}$ Rt. Vs $3^{\text {rd }}$ Rt. treatment sessions.

- Statistically significant ( $\mathrm{p}$-value $<0.05$ ) positive correlation between $1^{\text {st }} \mathrm{Rt}$. Vs $3^{\text {rd }}$ Rt. treatment sessions.
Table (6): Comparison between quality of life (QOL) before and after treatment

\begin{tabular}{|c|c|c|c|c|}
\hline Vari & Groups & $\begin{array}{c}\text { Before } \\
(\mathbf{N}=\mathbf{3 0})\end{array}$ & $\begin{array}{c}\text { After } \\
(\mathbf{N}=30)\end{array}$ & $\begin{array}{c}\text { T-test } \\
\text { p-value }\end{array}$ \\
\hline \multirow{2}{*}{ QOL } & Mean & 6.3 & 3.8 & \multirow{2}{*}{$0.001 *$} \\
\hline & $\pm \mathrm{SD}$ & 2.9 & 2.5 & \\
\hline
\end{tabular}

$*$ : p-value $<0.05$ is considered significant.

This table showed statistically significant difference ( $\mathrm{p}$-value $<0.05)$ between QOL before and after treatment.

Table (7): Comparison between QOL before and after treatment

\begin{tabular}{|c|c|c|c|c|}
\hline Vari & $\begin{array}{l}\text { Groups } \\
\text { les }\end{array}$ & $\begin{array}{c}\text { Before } \\
(\mathbf{N}=\mathbf{3 0})\end{array}$ & $\begin{array}{c}\text { After } \\
(\mathbf{N}=\mathbf{3 0})\end{array}$ & $\begin{array}{c}\text { T-test } \\
\text { p-value }\end{array}$ \\
\hline QOL & \begin{tabular}{|c|} 
Good \\
Moderate
\end{tabular} & $\begin{array}{l}19(63.3 \%) \\
11(36.7 \%)\end{array}$ & $\begin{array}{c}27(90 \%) \\
3(10 \%)\end{array}$ & $0.01 *$ \\
\hline
\end{tabular}

$*$ : p-value $<0.05$ is considered significant.

This table shows statistically significant

difference ( $\mathrm{p}$-value $<0.05$ ) between QOL before and after treatment.

Table (8): Correlation study between QOL and age (before treatment)

\begin{tabular}{|c|c|c|c|c|}
\hline \multicolumn{2}{|c|}{ Before treatment } & \multicolumn{2}{|c|}{ QOL } & \multirow[b]{2}{*}{$\begin{array}{c}\text { p- } \\
\text { value }\end{array}$} \\
\hline \multicolumn{2}{|l|}{ Variables } & $\begin{array}{c}\text { Good } \\
(\mathbf{N}= \\
19)\end{array}$ & $\begin{array}{c}\text { Moderate } \\
(\mathbf{N}=\mathbf{1 1})\end{array}$ & \\
\hline \multirow{2}{*}{$\begin{array}{c}\text { Age } \\
\text { (years) }\end{array}$} & Mean & 22.2 & 28.4 & \multirow{2}{*}{0.28} \\
\hline & \pm SD & 12.1 & 18.7 & \\
\hline
\end{tabular}

Table (8) showed no statistical significant difference ( $p$-value $>0.05$ ) between patients with good QOL and patients with moderate QOL as regards age before treatment.

Table (9): Correlation study between QOL and age (after treatment)

\begin{tabular}{|c|c|c|c|c|}
\hline \multicolumn{2}{|c|}{ After treatment } & \multicolumn{2}{|c|}{ QOL } & \multirow[b]{2}{*}{ p-value } \\
\hline \multicolumn{2}{|l|}{ Variables } & $\begin{array}{c}\text { Good } \\
(\mathbf{N}=\mathbf{2 7})\end{array}$ & $\begin{array}{c}\text { Moderate } \\
\quad(\mathbf{N}=\mathbf{3})\end{array}$ & \\
\hline & Mean & 23.3 & 35.3 & \\
\hline Age (yes & $\pm \mathrm{SD}$ & 12.9 & 29.02 & 0.18 \\
\hline
\end{tabular}

This table showed no statistical significant difference ( $p$-value $>0.05$ ) between patients with good QOL and patients with moderate QOL as regards age after treatment.

Table (10): Correlation study between QOL and sex (before treatment)

\begin{tabular}{|c|c|c|c|c|}
\hline \multirow{2}{*}{\multicolumn{2}{|c|}{$\begin{array}{l}\text { Before treatment } \\
\text { Variables }\end{array}$}} & \multicolumn{2}{|c|}{ QOL } & \multirow[b]{2}{*}{ p-value } \\
\hline & & \multirow{2}{*}{$\begin{array}{c}\begin{array}{c}\text { Good } \\
(\mathbf{N}=\mathbf{1 9})\end{array} \\
5(26.3 \%) \\
\end{array}$} & \multirow{2}{*}{$\begin{array}{c}\begin{array}{c}\text { Moderate } \\
(\mathbf{N}=\mathbf{1 1})\end{array} \\
3(27.3 \%)\end{array}$} & \\
\hline & Male & & & \\
\hline $\mathrm{Sc}$ & Female & $14(73.7 \%)$ & $8(72.7 \%)$ & 0.95 \\
\hline
\end{tabular}


This table showed no statistical significant difference ( $\mathrm{p}$-value > 0.05) between patients with good QOL and patients with moderate QOL as regards sex before treatment.

Table (11): Correlation study between QOL and sex (after treatment)

\begin{tabular}{|c|c|c|c||c|}
\hline \multicolumn{2}{|c|}{ After treatment } & \multicolumn{2}{c|}{ QOL } & \multirow{2}{*}{ p-value } \\
\cline { 3 - 4 } Variables & $\begin{array}{c}\text { Good } \\
(\mathbf{N = 2 7})\end{array}$ & $\begin{array}{c}\text { Moderate } \\
(\mathbf{N}=3)\end{array}$ & \\
\hline \multirow{2}{*}{ Sex } & Male & $8(29.6 \%)$ & $0(0 \%)$ & \multirow{2}{*}{0.27} \\
& Female & $19(70.4 \%)$ & $3(100 \%)$ & \\
\hline
\end{tabular}

Table (11) showed no statistical significant difference ( $p$-value $>0.05$ ) between patients with good QOL and patients with moderate QOL as regards sex after treatment.

\section{DISCUSSION}

The purpose of the present study was to compare the efficacy of PDL plus topical calcipotriol and corticosteroid combination versus topical calcipotriol and corticosteroid combination in the treatment of nail psoriasis.

The mean age of studied patients was $24.5 \pm$ 14.9 years and $77 \%$ of studied patients were females while $23 \%$ were males. $70 \%$ of studied patients were skin type 3 and the other $30 \%$ were type 4 .

To our knowledge, there are scanty studies that have either evaluated the efficacy of pulsed dye laser plus topical corticosteroids and calcipotriol in the treatment of nail psoriasis or compared topical corticosteroids and calcipotriol efficacy to PDL alone. The combination of laser and topical treatment can enhance the positive results of the therapy. Therefore, we used a coadjuvant treatment with betamethasone calcipotriol to improve the outcome.

Our study compared between right hands (received PDL plus topical combination) and left hands (received topical calcipotriol and corticosteroid combination daily). With respect to the number of treatment sessions; Modified NAPSI scores were slightly decreased in right hands between the $1^{\text {st }}, 2^{\text {nd }}$ and $3^{\text {rd }}$ sessions than in left hands of the patients. The mean of the score was $18.1,14.6$ and 15.1 in $1^{\text {st }}, 2^{\text {nd }}$ and $3^{\text {rd }}$ sessions of right hands treatment respectively, while the mean of the score was $16.3,13.8$ and 14.91 in $1^{\text {st }}, 2^{\text {nd }}$ and $3^{\text {rd }}$ sessions of left hands treatment respectively. But, there was no noted statistical significant difference ( $p$-value > 0.05) between right hand and left hand as regards treatment sessions. Also, there was no statistically significant difference (p-value > 0.05) between treatment sessions as regards total sessions.

A Comparison between Rt. hand and Lt. hand regarding follow up sessions showed that the mean was 14.5 and 14.6 in $1^{\text {st }}$ and $2^{\text {nd }}$ follow up of the Rt. hand respectively, while the mean was 14.8 and 15.2 in $1^{\text {st }}$ and $2^{\text {nd }}$ follow up of the Lt. hand. There were no differences between $1^{\text {st }}$ and $2^{\text {nd }}$ follow up in both hands and no statistically significant difference (p-value > 0.05 ) between right hand and left hand as regards follow up sessions. Also no statistically significant difference (p-value > 0.05) between follow up sessions as regards total. We found an improvement in the right hands with a slight difference that privileges PDL but the results were not statistically significant. These results suggest the benefits of this combination therapy, especially for those patients who have exclusive nail involvement. Erceg and colleagues ${ }^{(\mathbf{1 1})}$ compared the effectiveness of the PDL in the treatment of localized, recalcitrant plaque psoriasis with a potent topical therapy, using calcipotriol/betamethasone dipropionate (Dovobet) as an active comparator. A significant difference in the sum score 12 weeks after treatment was seen in favor of the PDL (62\% versus $19 \%$ reduction; $\mathrm{p}<0.05$ ). The authors concluded that PDL treatment might be considered for the treatment of localized, recalcitrant plaque psoriasis when other topical therapies have failed. Our data showed that 20 patients were $<30$ years old and 10 patients were $>30$ years old. Mean of Modified NAPSI scores decreased from 31.8 to 28.7 between $1^{\text {st }}$ and $3^{\text {rd }}$ in subgroup $<30$ years while mean of Modified NAPSI scores decreased from 39.7 to 32.6 between $1^{\text {st }}$ and $3^{\text {rd }}$ in subgroup $>30$ years with no statistically significant difference (p-value $>0.05)$ between the 2 subgroups ( $<30$ years and $>30$ years) as regard $1^{\text {st }}, 2^{\text {nd }}$ and $3^{\text {rd }}$ treatment session. As regards the sex our results showed better improvement in females $(n=22)$ than males $(n=8)$ no statistically significant difference ( $\mathrm{p}$-value $>0.05$ ) between the 2 subgroups (male and female) as regards treatment session.

Regards Skin type and outcomes of treatment in patients; The mean of Modified NAPSI scores decreased from 29.7 to 24.1 between $1^{\text {st }}$ and $3^{\text {rd }}$ in skin type 3 and scores decreased from 36.5 to 32.6 in skin type 4. However, no statistical significant difference (pvalue $>0.05$ ) between the 2 subgroups (skin type 3 and type 4) as regards treatment session. Ventura et al. ${ }^{(12)}$ stated that approximately $90 \%$ of psoriatic patients develop nail psoriasis during their lifetimes, and it is not related to gender or age.

In the present study, the correlation between treatment sessions at right hand showed highly statistically significant ( $\mathrm{p}$-value $<0.001$ ) positive correlation between 1st Rt. Vs 2nd Rt. and 2nd Rt. Vs 3rd Rt. treatment sessions. Also, statistically significant (p-value < 0.05 ) positive correlation between 1st Rt. Vs 3rd Rt. treatment sessions.

These results indicate that Increasing the number of PDL sessions accompanied by an increase in response in nail psoriasis treatment.

Before the start of treatment, the clinician should inform the patient that any noticeable nail improvement will take a long time and many treatments will show maximal results only after 1 year. The low growth rate of the nail plate is responsible for a delay of 3-9 months before clinical improvement can be noticed 
in cases of effective treatment. Four to 6 months is a reasonable period of treatment before evaluating clinically relevant results. In the beginning, the improvement may be so limited that it is advisable to take photographs of the nails during each visit to convince both the patient and the physician that the treatment has positive results.

In agreement with our results, Huang et al. ${ }^{(10)}$ evaluated the efficacy and safety of PDL with a topical retinoid in treating nail psoriasis in 25 patients with recalcitrant psoriasis of the bilateral fingernails. Marked reduction in mean NAPSI score from baseline to 6 months in the experimental group compared to the control group. A notably higher percentage of patients in the experimental group showed $\geq 75 \%$ improvement at 6 months versus the control group. Patient global assessment scores were higher in the experimental group versus the control group.

The quality of life data analysis showed highly statistically significant difference between QOL before and after treatment. The mean of QOL was $6.3 \pm 2.9$ and $3.8 \pm 2.5$ before and after treatment respectively. There was no statistical significant difference between patients with good QOL and patients with moderate QOL as regards mNAPSI score before and after treatment. There was no statistical significant difference between patients with good QOL and patients with moderate QOL before and after treatment as regards age and sex. Patients with only nail bed alterations scored significant lower QOL scores when compared to patients with only nail matrix features. The additional negative consequences of nail involvement in psoriasis on QOL may be explained by the fact that nail psoriasis is more than a highly visible variant. Complaints of patients with nail psoriasis include pain, inability to grasp small objects, tie shoe laces or button clothes and cause an altered sense of fine touch ${ }^{(13)}$.

Vitiello et al. (14) showed that the average baseline NAPSI score for the 13 patients was 22.3 and mNAPSI at week 0 was 6.3 . The mean NAPSI score at the end of week 12 was 14.8 and the mean mNAPSI score for the target nail was 5.2. The mean percentages of reduction of the NAPSI score and mNAPSI score were $31.8 \%$ and $13.3 \%$, respectively. At the end of week 12 , for two of the 13 patients (15\%), NAPSI scores remained the same. No improvement of the target nail's appearance was noted in $46 \%$ of the patients; however, the same amount of patients responded positively to treatment. De Jong et al. ${ }^{(5)}$ reported that 93\% of patients with psoriatic nail disease considered their condition to be a significant cosmetic handicap and to adversely impact their quality of life. The patientreported outcomes were also an important index of the efficacy of treatment. Though the patient's global assessment of psoriatic nail disease indicated significant improvement by experimental treatment over the control treatment. Only, $47.3 \%$ of patients receiving experimental treatment thought it improved fingernail cosmoses. This might mean that the improvement was not obvious enough or was incompatible with their expectations ${ }^{(5,10)}$.

Finally, the period of follow-up is of utmost importance in the judgment of the results because further improvement may occur up to 1 year. These reasons underline the need for studies in which several treatments are compared without other factors interfering with the outcome.

\section{CONCLUSION}

In conclusion, laser therapy has shown to be effective and safe for nail psoriasis. It could be used alone or combined with different therapeutic modalities, being especially beneficial with topical treatments.

\section{REFERENCES}

1. Griffiths CEM, Christophers E, Barker J et al. (2007): A classification of psoriasis vulgaris according to phenotype. $\mathrm{Br}$ J Dermatol., 156: 258-262.

2. Al-Mutairi N, Al-Haddad A (2013): Targeted phototherapy using $308 \mathrm{~nm}$ Xecl monochromatic excimer laser for psoriasis at difficult to treat sites. Lasers Med Sci., 28: 1119-1124.

3. Maejima H, Taniguchi T, Watarai A, Katsuoka K (2010): Evaluation of nail disease in psoriatic arthritis by using a modified nail psoriasis severity score index. Int J Dermatol., 49: 901-906.

4. Kerschbaumer A, Smolen JS, Aletaha D (2018): Disease activity assessment in patients with psoriatic arthritis. Ann Rheum Dis., 77 (12): 1736-1741.

5. De Jong E, Menke HE, Van Praag MCG, Van De Kerkhof PCM (1999): Dystrophic psoriatic fingernails treated with $1 \%$ 5-fluorouracil in a nail penetration-enhancing vehicle: a double-blind study. Dermatology, 199: 313-318

6. Peruzzo J, Garbin GC, Maldonado G, Cestari TF (2017): Nail psoriasis treated with pulsed dye laser. An Bras Dermatol., 92: 885-887

7. Radtke MA, Beikert FC, Augustin M (2013): Nail psoriasis-a treatment challenge. JDDG $\mathrm{J}$ der Dtsch Dermatologischen Gesellschaft, 11: 203-220.

8. Fernández- Guarino M, Harto A, Sánchez- Ronco M et al. (2009): Pulsed dye laser vs. photodynamic therapy in the treatment of refractory nail psoriasis: a comparative pilot study. J Eur Acad Dermatology Venereol., 23: 891-895

9. Oram Y, Karincaoğlu Y, Koyuncu E, Kaharaman F (2010): Pulsed dye laser in the treatment of nail psoriasis. Dermatologic Surg., 36: 377-381.

10. Huang YC, Chou CL, Chiang YY (2013): Efficacy of pulsed dye laser plus topical tazarotene versus topical tazarotene alone in psoriatic nail disease: A single-blind, intrapatient leftto-right controlled study. Lasers Surg Med., 45: 102-107.

11. Erceg A, Bovenschen HJ, Van De Kerkhof PCM, Seyger MMB (2006): Efficacy of the pulsed dye laser in the treatment of localized recalcitrant plaque psoriasis: a comparative study. Br J Dermatol., 155: 110-114

12. Ventura A, Mazzeo M, Gaziano R et al. (2017): New insight into the pathogenesis of nail psoriasis and overview of treatment strategies. Drug Des Devel Ther., 11: 25-27.

13. Pasch MC (2016): Nail psoriasis: a review of treatment options. Drugs, 76: 675-705.

14. Vitiello M, Tosti A, Abuchar A et al. (2013): Ustekinumab for the treatment of nail psoriasis in heavily treated psoriatic patients. Int J Dermatol., 52: 358-362. 